\title{
Operacionalização da logística reversa entre uma empresa eólica e uma cooperativa de catadores
}

\author{
Operationalization of reverse logistics of a wind company and a \\ cooperative of waste pickers
}

\author{
Nicole Rios Tavares \\ nicolertavares@yahoo.com.br \\ Universidade de Fortaleza

\section{Leite \\ dricaoliver@unifor.br \\ Universidade de Fortaleza} \\ Adriana de Oliveira Sousa
}

\begin{abstract}
Resumo
Esta pesquisa apresenta um estudo das vantagens da doação dos resíduos sólidos recicláveis de uma empresa privada para uma cooperativa, que possui geração frequente desses resíduos, no caso, uma empresa do ramo de energia eólica. A destinação final adequada dos resíduos sólidos sempre foi um desafio, e é um dos grandes problemas enfrentados atualmente, devido ao descarte incorreto em áreas inapropriadas. A geração dos resíduos aumentou bastante com o desenvolvimento tecnológico, e como alternativa para a diminuição do volume e o descarte ambientalmente correto, a prática da logística reversa é considerada a mais indicada, por incentivar a reutilização dos resíduos e, consequentemente, prolongar a vida útil dos produtos. Essa prática é o grande estímulo para a ação das cooperativas de catadores, que geram renda na comercialização desses resíduos para as indústrias recicladoras, e com isso são papéis importantes para manter a sustentabilidade do planeta. Foi constatado que os resultados dessa doação reduziram o custo da empresa com a destinação correta dos seus resíduos e trouxe, também, para a cooperativa o lucro, a partir da reciclagem desses resíduos sólidos.
\end{abstract}

Palavras-chave: Logística reversa. Custo. Cooperativa. Resíduos sólidos.

\begin{abstract}
This research presents a study of the donation of the advantages of recyclable solid waste from a private company to a cooperative, which has frequent generation of waste, in this case, a company in the wind energy business. Proper disposal of solid waste has always been a challenge, and is one of the major problems currently facing due to incorrect disposal in inappropriate areas. The generation of waste has increased significantly with technological development, and as an alternative to reduce the volume and environmentally friendly disposal, the practice of reverse logistics is considered the most appropriate, to encourage the reuse of waste and thus extend the life of the products. This practice is the great stimulus to the action of recycling cooperatives that generate income in the marketing of such waste to the recycling industries, and these are important roles to maintain the sustainability of the planet. It was found that the results of this donation reduced the cost of the company with the proper disposal of their waste and brought also to the cooperative profit from the recycling of such waste.
\end{abstract}

Keywords: Reverse logistics. Cost. Cooperative. Solid waste.

\section{Introdução}

A geração de resíduos sólidos é um problema comum e bastante frequente no cotidiano dos brasileiros. Com o crescimento industrial e o desenvolvimento do país, essa geração se torna bem mais intensa; além do aumento na quantidade de resíduos, a destinação inadequada destes é uma das causas para o problema da poluição ambiental.

Esta geração desenfreada de resíduo criou oportunidades para o aumento de renda para uma classe de trabalhadores, que até então estava às margens da sociedade, os catadores de resíduos, que se utilizam da logística reversa para o reaproveitamento dos resíduos, comercializando-os para as empresas recicladoras. 
O mercado eólico é um dos empreendimentos que possui significativo impacto ambiental relacionado à geração dos resíduos, tanto na fase de instalação quanto na fase de operação; e, principalmente, na sua desinstalação. A caracterização desses resíduos assinala que a maioria deles está relacionada aos elementos de difícil degradação (não inertes), no entanto, necessita de tratamentos mais direcionados. A reciclagem é uma das possibilidades sugeridas e a mais adotada, por ser considerada ambientalmente correta.

Essas empresas do ramo de energia eólica, assim como as demais, são obrigadas, por lei, a dar a destinação final adequada aos seus resíduos, o que normalmente gera um custo alto aos seus cofres. Esses custos estão atrelados à contratação de prestadores de serviços especializados na atividade, desde o transporte adequado até o seu destino final, propriamente. Tais empresas estão sujeitas a despesas com licenças ambientais, contratos de empresas de transportes, aluguéis de coletores, destino final e toda a operacionalização interna para que a separação possa ser feita.

Visando à diminuição desses custos e, ao mesmo tempo, ao desenvolvimento de ações de responsabilidade social, este trabalho apresentará certos benefícios da doação dos resíduos sólidos para cooperativas de catadores.

A energia eólica, no Brasil, teve seu primeiro indício em 1992, com o início da operação comercial do primeiro aero gerador instalado no Brasil, que foi resultado de uma parceria entre o Centro Brasileiro de Energia Eólica (CBEE) e a Companhia Energética de Pernambuco (CELPE), através de financiamento do instituto de pesquisas dinamarquês Folkecenter. Essa turbina eólica, de $225 \mathrm{KW}$, foi a primeira a entrar em operação comercial na América do Sul, em 1992, localizada no arquipélago de Fernando de Noronha - Pernambuco. (ABEEÓLICA, 2013).

Levando em consideração o mercado eólico, uma determinada empresa do ramo adotou como política ambiental o programa de coleta seletiva que foi implantado de acordo com a Associação Brasileira de Normas Técnicas (ABNT-NBR 10.004:2004) e o código de cores para os diferentes tipos de resíduos, determinado na Resolução CONAMA n ${ }^{\circ} 275$, de 25 de abril de 2001. Os resíduos gerados nessa empresa são, basicamente, os de classe I e II, inertes e não inertes, os quais oneram as contas financeiras desta empresa, pois a coleta, transporte e destinação final dos resíduos são elevados e não podem ser eliminados.

Segundo a Lei $n^{\circ}$ 12.305/2010 - Politica Nacional dos Resíduos Sólidos (PNRS), art. 3º, inciso XII, a logística reversa é definida como um instrumento de desenvolvimento econômico e social caracterizado por um conjunto de ações, procedimentos e meios destinados a viabilizar a coleta e a restituição dos resíduos sólidos ao setor empresarial, para reaproveitamento, em seu ciclo ou em outros ciclos produtivos, ou outra destinação final ambientalmente adequada.

A PNRS apresenta o instrumento da logística reversa como sendo uma ferramenta a ser adotada para a coleta dos resíduos sólidos gerados no Brasil, incluindo as embalagens pós-consumo. A Lei Federal 12.305/2010 define a logística reversa em seu Artigo $3^{\circ}$, parágrafo XII, como: “instrumento de desenvolvimento econômico e social caracterizado por um conjunto de ações, procedimentos e meios destinados a viabilizar a coleta e a restituição dos resíduos sólidos ao setor empresarial, para reaproveitamento, em seu ciclo ou em outros ciclos produtivos, ou outra destinação final ambientalmente adequada". PNRS estabelece responsabilidades para os diferentes atores na logística reversa, onde cada um deverá comprometer-se com o desenvolvimento de suas ações para o êxito da implementação do sistema (NETO, 2011). A Figura 1 apresenta o fluxo da logística reversa, sendo que os consumidores devem efetuar a devolução de produtos e embalagens aos comerciantes e distribuidores, que, por sua vez, devem devolver ao fabricante ou importador e, por fim, o fabricante ou importador deve dar destinação ambientalmente adequada aos produtos e embalagens devolvidos.

Figura 1 - Fluxo da logística reversa.

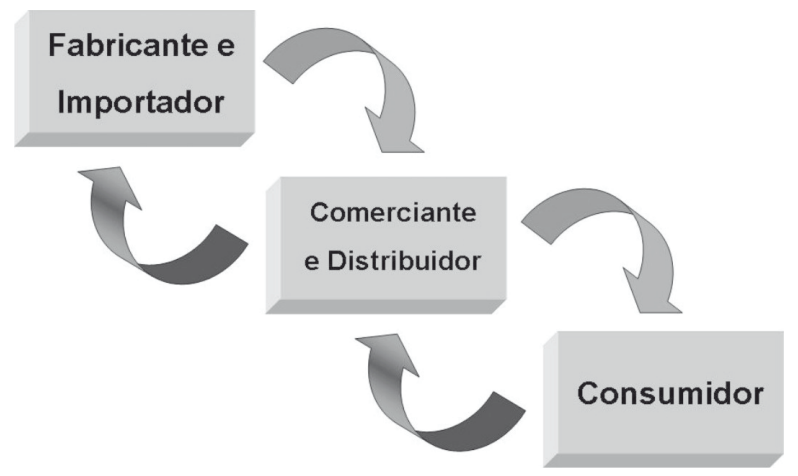


Segundo a Lei Federal 12.305/2010, a logística reversa deve ser aplicada independente do serviço público de limpeza urbana. Então, os fabricantes, importadores, distribuidores e comerciantes são obrigados a organizar a cadeia produtiva para receberem de volta os resíduos sólidos que forem contemplados na logística reversa. Conforme a PNRS, já são obrigados a implementar o sistema de logística reversa os resíduos sólidos de pilhas e baterias, óleos lubrificantes, pneus, lâmpadas, contendo mercúrio, eletroeletrônicos e agrotóxicos e seus resíduos e embalagens, assim como outros produtos cuja embalagem, após o uso, constitua resíduo perigoso.

A logística reversa é obrigatória para os resíduos citados anteriormente, porém a PNRS sinaliza que os resíduos de plásticos, metal e vidro são, também, passíveis de ter logística reversa, ou seja, não há obrigatoriedade a sua implementação nesse momento. É importante levar em conta que hoje a coleta seletiva de resíduos, principalmente de metais, vidros, plásticos e papéis, já contribui para o funcionamento da logística reversa, sendo uma alternativa de renda para as cooperativas de triagem e reciclagem de resíduos.

A geração de resíduos sólidos tende a aumentar com o desenvolvimento industrial, e a melhor solução para essa problemática é que sua destinação final siga de forma adequada e alinhada com os quesitos ambientais, não esquecendo o olhar para as despesas e custos, de tal forma que tanto as diretrizes do meio ambiente quanto os resultados financeiros sejam satisfatórios para as empresas geradoras de resíduos, envolvendo as atividades determinadas no conceito de logística reversa (SANTOS, 2012).

A Associação Brasileira de Normas Técnicas (ABNT) NBR 10.004 (2004) classifica os resíduos sólidos de acordo com o risco que oferecem (PAIVA, 2011):

Resíduos classe I - perigosos: são aqueles que, em função de suas características intrínsecas, apresentam riscos à saúde ou ao meio ambiente.

Resíduos classe II - não inertes: são aqueles que podem apresentar características de combustibilidade, biodegradabilidade ou não solúveis na água ou ao meio ambiente, não se enquadrando nas classificações de resíduos classe I - perigosos ou classe III - inertes.

Resíduos classe III - inertes: são aqueles que, por suas características intrínsecas, não oferecem risco à saúde, e que apresentam constituintes solúveis em água e em concentrações superiores aos padrões de potabilidade.

A adequada destinação desses resíduos é um dos grandes desafios da humanidade. E, no caso do Brasil, o desafio é ainda maior, pois poucos são os casos de destinação final correta dos resíduos sólidos industriais.

A legislação invoca o princípio da responsabilidade do gerador, que trata a responsabilidade desde a geração, estocagem, armazenamento, transporte e tratamento, até sua disposição final. O tratamento dos resíduos sólidos é importante para a diminuição da sua quantidade e da poluição do material, quando aterrado. As vantagens desse tratamento adequado não são somente ambientais, mas também econômicas, pois devido à redução de custos com a disposição final, essa vantagem econômica se sobressai (PAIVA, 2011).

Como método de tratamento dos resíduos sólidos, em seu destino final, o mais adequado a se adotar, do ponto de vista sanitário e ambiental, é a reciclagem, por ser ambientalmente correta e praticar a reutilização como forma de prolongar o ciclo de vida do produto.

De acordo com a Lei no 12.305 , de 2 de agosto de 2010, Política Nacional de Resíduos Sólidos, art 3º, inciso XIV, a reciclagem é o processo de transformação dos resíduos sólidos, o qual envolve a alteração de suas propriedades físicas, físico-químicas ou biológicas, com vistas à transformação em insumos ou novos produtos, observadas as condições e os padrões estabelecidos pelos órgãos competentes do Sistema Nacional do Meio Ambiente (SISNAMA) e, se couber, do Sistema Nacional de Vigilância Sanitária (SNVS) e do Sistema Único de Atenção à Sanidade Agropecuária (SUASA). Segundo os cientistas, há dois tipos de resíduos que podem ser reciclados. O resíduo pré-consumo ou interno é gerado em um processo de fabricação e reciclado ao invés de ser descartado. O resíduo pós-consumo ou externo é gerado pelo consumo dos produtos. Existe cerca de 25 vezes mais resíduos pré-consumo do que pós-consumo. É importante reciclar ambos os tipos. (MILLER JR, 2008).

Como exemplos de resíduos pós-consumo, podem ser citados, a partir dos dados fornecidos pelo Conjunto Vida Nova de Maracanaú - COOMVIDA (2013), os resíduos recicláveis gerados na empresa eólica foram listados na Tabela 01 .

O modelo de gestão de resíduos sólidos, definido pela Lei Federal 12.305/2010 e que veio a ser regulamentado pelo Decreto Federal 7404/2010, consolida papéis extremamente importantes para as cooperativas de reciclagem, onde seu envolvimento e comprometimento poderão determinar o êxito da implementação da PNRS. Os principais mecanismos 
de operacionalidade da PNRS, tanto da coleta seletiva como da logística reversa, priorizam a participação e a atuação estratégica e incisiva dos catadores de resíduos e suas cooperativas (NETO, 2011).

De acordo com a Lei n ${ }^{\circ} 5764 / 1971$ (art. 4º), as cooperativas são sociedades de pessoas, com forma e natureza jurídica próprias, de natureza civil, não sujeitas à falência, constituídas para prestar serviços aos associados, distinguindo-se das demais sociedades. Pode-se, ainda, citar que a mesma legislação (art. $1^{\circ}$ ) define a Política Nacional de Cooperativismo como a atividade decorrente das iniciativas ligadas ao sistema cooperativo, originárias de setor público ou privado, isoladas ou coordenadas entre si, desde que reconhecido seu interesse público.

Além da possibilidade de envolvimento dos catadores na logística reversa, outro papel importante é a participação de forma prioritária dos catadores e suas cooperativas nos sistemas de coletas seletivas, conforme o Artigo 11 do Decreto Federal No $\mathrm{N}^{\circ} 7404 / 2010$. Antes da vigência da PNRS, outros instrumentos legais já criavam oportunidades para fomentar a participação de catadores de resíduos sólidos nos processos de gestão ambiental e na inclusão social e econômica e melhoria das condições de trabalhos dos catadores. O Decreto Federal No 5940/2006 institui que entidades da administração pública federal destinem seus resíduos recicláveis para associações e cooperativas dos catadores de materiais recicláveis. Esse fator alavancou o numero de cooperativa e associações de catadores no Nordeste, como apresentado na Tabela 2.

Tabela 1 - Resíduos recicláveis gerados na empresa eólica e doados para a cooperativa.

\begin{tabular}{ll}
\hline \multicolumn{1}{c}{ RESÍDUOS RECICLAVEIS } & \multicolumn{1}{c}{ EXEMPLOS } \\
\hline Papel Branco & Papel ofício para impressões \\
\hline Papel Misto & Papel reciclado para impressões \\
\hline Papelão & Caixas para embalagens \\
\hline PET & Garrafas de sucos ou refrigerantes \\
\hline Plástico Rígido & Embalagens de produtos \\
\hline Plástico filme branco & Sacos de lixo \\
\hline Plástico filme preto & Sacos de lixo \\
\hline Alumínio & Embalagens de quentinhas \\
\hline
\end{tabular}

Fonte: COOMVIDA, 2013.
Tabela 2 - Número de cooperativas e associações de catadores em cada município do Nordeste.

\begin{tabular}{lccc|}
\hline & $\begin{array}{c}\text { Cooperativas ou } \\
\text { associaços de } \\
\text { catadores }\end{array}$ & $\begin{array}{c}\mathbf{N}^{\circ} \text { de cooperativas } \\
\text { ou Associaçôes }\end{array}$ & $\begin{array}{c}\mathbf{N}^{\circ} \text { de catadores } \\
\text { ligados a } \\
\text { cooperativas ou } \\
\text { Associaçōes }\end{array}$ \\
\hline Nordeste & 106 & 154 & 4861 \\
\hline Maranhão & 7 & 8 & 355 \\
\hline Piaui & 2 & 2 & 90 \\
Ceará & 21 & 36 & 922 \\
\hline Rio Grande do Norte & 6 & 10 & 329 \\
\hline Paraíba & 8 & 9 & 608 \\
\hline Pernambuco & 32 & 39 & 1096 \\
\hline Alagoas & 3 & 5 & 90 \\
\hline Sergipe & 1 & 1 & 45 \\
Bahia & 26 & 44 & 1326 \\
\hline
\end{tabular}

Fonte: COOMVIDA, 2013.

As primeiras experiências associativas de catadores no Brasil iniciaram-se em São Paulo, Porto Alegre e Belo Horizonte (JACOBI; VIVEIROS, 2006). Em São Paulo, por meio do trabalho de apoio à população de rua, desenvolvido pela Organização de Auxilio Fraterno (OAF), foi criada a Associação dos Catadores de Papel, em 1986. Em Porto Alegre, no ano de 1986, foi criada a Associação dos Catadores de Material de Porto Alegre, na Ilha Grande dos Marinheiros, com o apoio do trabalho eclesial de base da Igreja Católica (MARTINS, 2003). Em Belo Horizonte, depois do trabalho de apoio aos catadores realizado pela Pastoral de Rua, em 1990, foi constituído a Associação dos Catadores de Papel, Papelão e Material Reaproveitável (ASMARE) (PEREIRA; TEIXEIRA, 2011).

A partir do final da década de 1990 e nos anos 2000, os catadores foram se articulando com apoio de uma rede de organizações da sociedade civil e formaram o Movimento Nacional dos Catadores de Materiais Recicláveis (MNCR), em 2001 (ARAÚJO; SAMPAIO, 2013).

Segundo o levantamento do Instituto de Pesquisa Econômica Aplicada, IPEA, há atualmente entre 400 e 600 mil catadores de materiais recicláveis no Brasil, sendo que ao menos 1.100 organizações coletivas de catadores estão em funcionamento em todo o país. Entre 40 e 60 mil catadores participam de alguma organização coletiva, isto representa apenas $10 \%$ da população total de catadores. A renda média dos catadores, aproximada a partir de estudos parciais, não atinge o salário mínimo, alcançando entre $\mathrm{R} \$ 420,00$ e $\mathrm{R} \$ 611,00$, a faixa de instrução mais observada entre os catadores vai da $5^{\mathrm{a}}$ a $8^{\mathrm{a}}$ séries (GARCIA, 2014).

O trabalho desenvolvido por eles reduz os gastos do governo com o sistema de limpeza pública, aumenta a vida útil dos aterros sanitários, diminui a demanda por recursos naturais e fomenta a cadeia produtiva das indústrias recicladoras com material reciclável de baixo custo e com a geração de trabalho (BONIN, 2012).

Não há uma estatística precisa acerca do contingente total de catadores de recicláveis no Brasil. As estimativas variam muito, de modo que a construção de um quadro mais realista desta atividade requer um olhar crítico sobre 
as informações disponíveis em fontes diversas. A Tabela 3 traz os resultados levantados pelo Instituto Brasileiro de Geografia e Estatística - IBGE (IPEA, 2012) em relação ao numero de catadores até 2012.

Tabela 3 - Número de catadores maiores e menores de 14 anos em cada municínio do Nordeste.

\begin{tabular}{lccc}
\hline & $\begin{array}{c}\mathbf{N}^{\circ} \text { de catadores até } \\
\text { anos de idade }\end{array}$ & $\begin{array}{c}\mathbf{N}^{\circ} \text { de catadores com } \\
\text { mais de 14 anos de } \\
\text { idade }\end{array}$ & TOTAL \\
\hline Nordeste & 1553 & $\mathbf{1 2 3 4 4}$ & $\mathbf{1 3 8 9 7}$ \\
\hline Maranhão & 39 & 655 & 694 \\
\hline Piauí & 20 & 128 & 148 \\
\hline Ceará & 93 & 1096 & 1189 \\
Rio Grande do Norte & 24 & 665 & 689 \\
\hline Paraíba & 70 & 1244 & 1314 \\
\hline Pernambuco & 1012 & 5789 & 6801 \\
\hline Alagoas & 44 & 386 & 430 \\
\hline Sergipe & 36 & 575 & 611 \\
\hline Bahia & 215 & 1806 & 2021 \\
\hline
\end{tabular}

Fonte: IPEA, 2012

Há diversos modos para atuação dos catadores, e em todos os estágios do sistema de manejo, entre eles: separação na fonte, contêineres de lixo, coleta das ruas, espaços públicos, terrenos baldios, em rios e córregos, em lixões e aterros. Os catadores encontram-se expostos a condições insalubres, que acarretam para o grupo uma maior taxa de morbidade e mortalidade que a média da população.

Além das más condições de trabalho, outros problemas enfrentados pelos catadores são a exclusão social e o entorno social hostil, sendo vistos com desprezo, confundidos com mendigos e infratores. Esses trabalhadores enfrentam uma situação paradoxal. Por um lado, são responsáveis pela transformação do lixo em mercadoria de interesse de grandes indústrias, que tanto lhes confere um papel central de um amplo circuito relativo à produção e ao consumo de bens, como caracteriza os catadores como verdadeiros agentes ambientais ao efetuarem um trabalho essencial no controle da limpeza urbana. Por outro lado, esses trabalhadores ocupam uma posição marginal na sociedade, com poucas oportunidades no mercado de trabalho, dadas suas carências em termos de formação profissional, bem como por serem pobres e relegados para espaços geográficos suburbanos e marginalizados, sofrerem diferentes tipos de exclusão no mercado de consumo e na dinâmica das relações sociais.

Ao longo dos anos, no intuito de reverter essa situação de exclusão social em suas diversas dimensões, os catadores de material reciclável vêm buscando se articular coletivamente com base em diferentes formatos organizacionais, visando à superação de gargalos estruturais que lhes impedem de se apropriarem de um maior valor por seu trabalho. Isso porque, ao se organizarem, os catadores conseguem estabelecer relações de mercado diferenciadas, além de poderem inclusive avançar em alguns elos no âmbito da cadeia produtiva, com a agregação de valor ao material reciclável por meio de algum processo de beneficiamento.

A organização dos catadores também é importante na medida em que lhes propicia maior capacidade de mobilização para negociarem com o poder público e com outros setores da sociedade, na busca de parcerias e políticas governamentais para sua maior valorização enquanto categoria profissional e sujeitos detentores de direitos. Em ambos os casos foi de fundamental importância o envolvimento de grupos da sociedade civil, em especial das pastorais de rua da Igreja Católica, que auxiliaram na formação das primeiras articulações de catadores (BENVINDO, 2010).

O método de cooperação entre um grupo de pessoas baseia-se na ação conjunta, no trabalho coletivo de indivíduos associados livremente, para pôr em marcha a obtenção de melhores condições econômicas, sociais, morais e civis, por meio de suas forças, a fim de prestar uma série de serviços. O movimento associativista está apoiado numa filosofia nova, ou seja, seu propósito é fazer vingar uma transformação pacífica, porém radical, das condições econômicas e sociais criadas pelo lucro desordenado dos capitalistas, no qual prevalece a exploração do homem (SANTOS, 2012).

Há estudos que mostram a dificuldade das cooperativas, uma vez que os catadores têm baixa escolaridade, histórico de exclusão social e dificuldades no estabelecimento de vínculos e compromissos com a cooperativa, pois trabalhando como autônomo não têm de se submeter a regulamentos e conseguem obter ingressos financeiros, ainda que muito baixos, diária ou semanalmente, ao vender o material coletado para o atravessador (SIMAN; PENNA, 2011). 
Diante disso, pode-se perceber a importância das cooperativas para o desenvolvimento sustentável, através da promoção de melhoria de vida dos cooperados, geração de empregos e melhores condições de trabalho, e diminuição dos passivos ambientais provenientes da geração descontrolada dos resíduos sólidos, que hoje possuem como destinação mais comum o aterro sanitário.

\section{Metodologia}

Para o presente estudo, foi necessário fazer um levantamento das associações locais que trabalhavam com reciclagem, sempre mediante contato com a Prefeitura Municipal.

Em contato com a Secretaria do Meio Ambiente do município de Maracanaú e a de Fortaleza, encontramos informações de duas cooperativas de catadores de resíduos; uma localizada em Maracanaú e outra localizada em Fortaleza.

Diante dessas informações, foi estabelecido um contato inicial com as cooperativas, a fim de marcamos o primeiro encontro para a apresentação do projeto. Nesse primeiro momento, apresentamos a ideia do projeto, analisamos a documentação das cooperativas, conhecemos a forma e as condições de trabalho que os cooperados estavam submetidos, checamos a responsabilidade e a utilização de EPI (Equipamentos de Proteção Individual), finalizando com a análise da metodologia de separação, compactação e armazenamento dos materiais.

Diante de todo esse levantamento, foi montada uma apresentação global das alternativas disponíveis à empresa requerente, dos prováveis ganhos e das necessidades a serem implantadas.

\subsection{Caracterização da cooperativa}

A cooperativa de produção dos catadores do Conjunto Vida Nova de Maracanaú (COOMVIDA) é uma cooperativa destinada a realizar coleta, transporte, triagem, beneficiamento, armazenamento e comercialização de materiais recicláveis e reutilizáveis, possuindo licença ambiental para isso. Localizada nas dependências do Aterro Sanitário de Maracanaú, iniciou suas atividades em $1^{\circ}$ de julho de 2003 com 110 cooperados e hoje em dia estão trabalhando apenas cerca de 30 cooperados.

O objetivo do COOMVIDA é prestar serviços aos seus cooperados, com base na colaboração recíproca dos mesmos, proporcionando-lhes condições de trabalho e geração de renda, promovendo a capacitação, o aperfeiçoamento profissional, o desenvolvimento das atividades econômicas e sociais e a melhoria das condições de vida de seus associados. E alguns dos seus maiores desafios enfrentados atualmente são receber receitas atrasadas e resgatar outros cooperados para retornar com o trabalho na usina-cooperativa; pagar seus fornecedores; realizar a manutenção de caminhões, tratores, prensas, esteiras; aumentar a produtividade de recicláveis com novos doadores; promover aos cooperados cursos fundamental, médio e técnico; e outras metas para o desenvolvimento tecnológico na operacionalização da cooperativa.

\subsection{Alterações dos contratos vigentes}

Após a aprovação da cooperativa pela empresa, foi necessária a revisão do contrato com a empresa encarregada pela coleta, transporte e destinação dos resíduos, para modificar a periodicidade dos serviços vinculados aos resíduos recicláveis em um período de teste da cooperativa, durante cinco meses. Após avaliação do período de adaptação da cooperativa e da empresa eólica, o contrato com a prestadora de serviço foi discutido novamente, com o propósito de finalizar os serviços atrelados aos resíduos recicláveis e os novos preços, para resíduos perigosos e comuns que não estavam no escopo do projeto.

\subsection{Alterações do procedimento interno de coleta}

O acordo com a cooperativa foi assinado e não foi necessária nenhuma mudança nas instalações do armazenamento interno dos resíduos na empresa.

A frequência de coleta dos resíduos recicláveis ficou estabelecida com a periodicidade semanal, devido à geração frequente e elevada. Para qualquer necessidade extra de coleta, a solicitação seria feita por meio de contato telefônico ou e-mail. 
Os resultados da logística de doação dos resíduos a cooperativa serão acompanhados através de relatórios mensais enviados a empresa.

Internamente, foi feita a divulgação da nova sistemática adotada com o uso de mídia eletrônica (jornal interno).

\section{Resultados e discussões}

A cooperativa de produção dos catadores do COOMVIDA foi escolhida para receber os resíduos doados pela empresa. $\mathrm{Na}$ visita realizada ao local, foi possível conhecer, além das instalações físicas, a seriedade e o comprometimento de todos os envolvidos dentro da cooperativa.

O COOMVIDA iniciou sua operação na empresa em fevereiro de 2013, estendendo-se até os dias atuais. Nos primeiros meses, foi realizado um período de teste que durou cinco meses (fevereiro a junho de 2013), e a partir de julho de 2013 a operacionalização da coleta, transporte e destinação final dos resíduos recicláveis passou, na sua totalidade, para a responsabilidade da cooperativa.

Com informações passadas pelos responsáveis pelo COOMVIDA, verificou-se que eles possuem uma grande dificuldade de manter os catadores trabalhando na cooperativa, pois a renda deles é bastante oscilante, devido à dependência do volume dos resíduos doados pelos parceiros.

Em 2012, eles tiveram um faturamento médio mensal de R\$9.000,00. Com esse valor pagaram fornecedores, realizaram a manutenção dos caminhões, tratores, prensas e esteiras, bem como realizaram o pagamento dos cooperados, os quais no ano em questão tiveram uma média salarial de R \$ 622,00 por mês. Essa A permanência de cooperados junto à cooperativa é um problema instaurado no Brasil; outras cooperativas percebem que, embora exista uma grande procura para fazer parte da associação, o número de trabalhadores não é maior para não influenciar na renda dos participantes já existentes, conforme relatado por Silva e Penna (2013), quando avaliam coleta seletiva em Governador Valadares/MG.

Após uma avaliação da estrutura física da cooperativa, verificamos uma série de dificuldades e necessidades que poderiam alavancar o negócio. A Figura 2 mostra a fachada da edificação do COOMVIDA, na qual se pode perceber a falta de manutenção atribuída à ausência de recursos. Na Figura 3, observa-se a esteira que é utilizada para os catadores realizarem a separação dos resíduos que chegam à cooperativa, a mesma apresenta baixa capacidade. A Figura 4 mostra alguns catadores trabalhando na separação desses resíduos, alguns destes sem os equipamentos de segurança necessários. Na Figura 5, estão os resíduos já pesados e armazenados para comercialização.

Um ponto a ser levado em consideração foi o baixo número de parceiros que o COOMVIDA possuía para comercializar todos os tipos de resíduos. Para extrair o máximo das doações, eram necessárias mais pessoas, pois a prestadora de serviço só possuía uma recicladora como receptora dos resíduos.

Esses foram alguns dos pontos de melhoria evidenciados na implantação do projeto, entretanto, muitos são os problemas enfrentados pelas cooperativas brasileiras, dentre os quais: maquinário com defeito e o espaço destinado à separação do material ser insuficiente para comportar os trabalhadores. Muitas vezes, o processo ocorre na área externa do galpão, ao ar livre, estando sujeito à ação do tempo, como chuva e sol intensos, tornando os resíduos muitas vezes inutilizáveis - são problemas que tornam os projetos de parceria empresa-cooperativa inválidos, pois as falhas administrativas dos cooperados não proporcionam crescimento da empresa cooperativa, e a empresa que necessita destinar os resíduos ficam descobertas (HEIDEN, 2007). Esses fatos podem ser justificados pela pouca experiência das diretorias das cooperativas, variações no mercado comprador, falta de capital de giro de forma a assegurar um rendimento mínimo aos catadores, baixo investimento em condições de processo e ainda falta de perspectiva de novas parcerias.

Para o acompanhamento e controle dos resíduos doados para o COOMVIDA, foi estabelecido o envio de um relatório padrão mensal feito pela empresa EOLICA e envio a cada carga encaminhada, a fim de estabelecer o controle de quantidade, no qual constavam todas as informações referentes às coletas realizadas, assim como o peso dos resíduos coletados, o tipo dos resíduos e a quantidade arrecadada pela cooperativa com esses resíduos. 
Figura 1: Fachada do COOMVIDA.

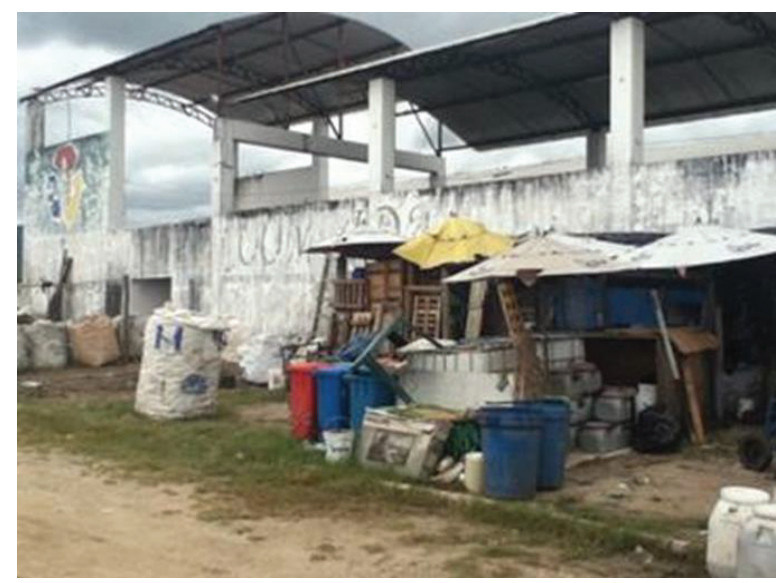

Fonte: Arquivo pessoal, 2012.

Figura 3: Cooperados trabalhando na separação dos resíduos na cooperativa.

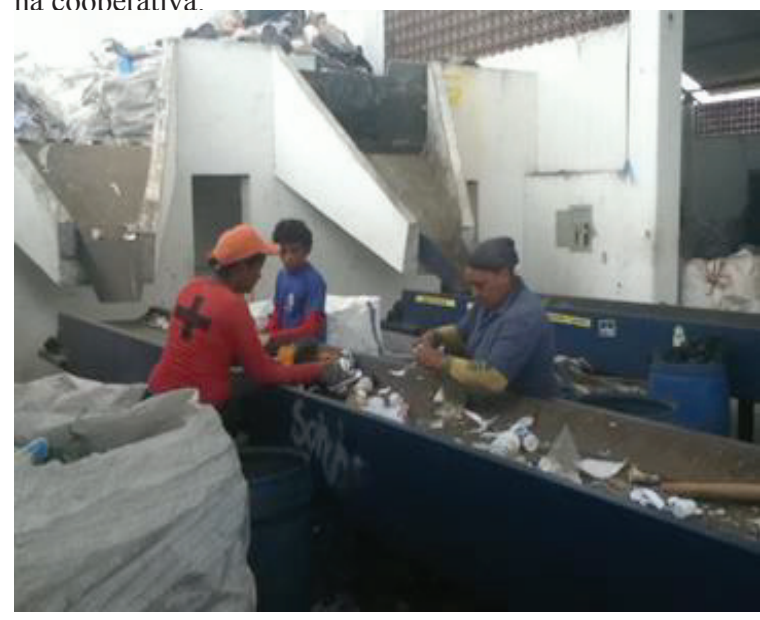

Fonte: Arquivo pessoal, 2012.
Figura 2: Esteira pela qual passa os resíduos para serem senarados.

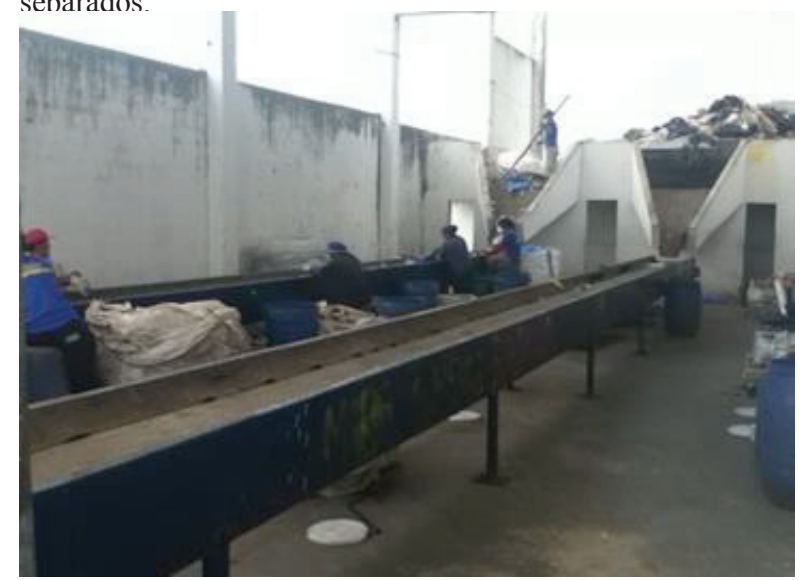

Fonte: Arquivo pessoal, 2012.

Figura 4: Resíduos organizados para comercialização.

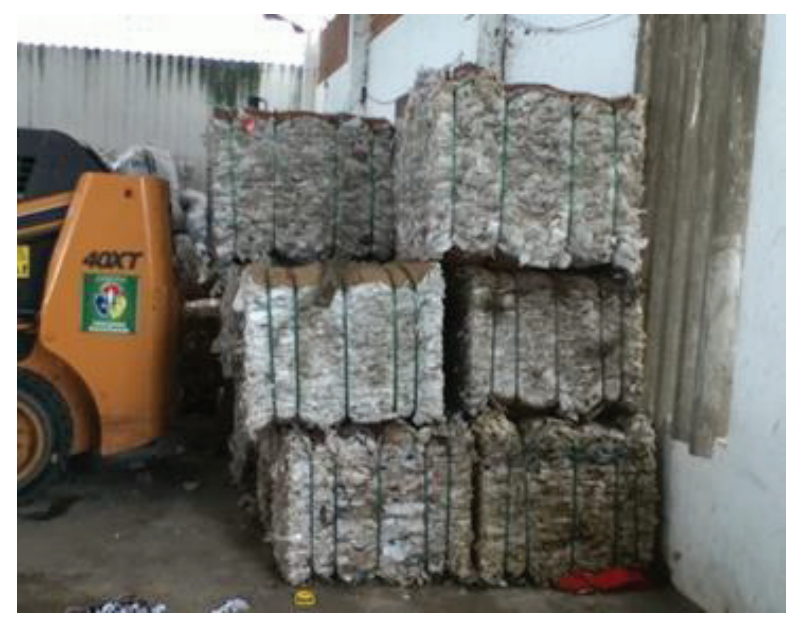

Fonte: Arquivo pessoal, 2012.

Dentre os resíduos doados, são vários os tipos e volumes que interessam à cooperativa, os mais comuns e que são gerados em uma maior quantidade estão descriminados do Gráfico 1 . No período de fevereiro a outubro de 2013 , foram coletadas e destinadas mais de duas toneladas de resíduos recicláveis, da empresa de energia eólica, e mais da metade desses resíduos foi doada ao COOMVIDA. O valor do quilograma do resíduo no estado ainda é muito baixo. Como é possível observar na Tabela 4, esses valores não permitem uma elevada lucratividade da cooperativa.

Assim como o COOMVIDA, outras cooperativas que trabalham em parceria com empresas (industriais) arrecadam na sua totalidade papel, plástico e metais (SIMAN, 2013). Esses tipos de materiais são bastante utilizados em embalagens múltiplas, utilizadas para proteção dos produtos e distribuição, conferindo praticidade e atratividade, mas ao mesmo tempo aumentando a produção de resíduos sólidos.

Realizando um comparativo quanto à geração, pode-se observar que houve, em 2013, um aumento nos pesos dos resíduos recicláveis. Considerando que não foi registrada nenhuma atividade diferente das já executadas pela empresa, pode-se apontar que a cooperativa faz uma melhor separação dos resíduos que recebe da empresa, pois os pesos declarados mensalmente por eles são maiores do que eram declarados pela outra empresa terceirizada que prestava serviço de coleta, transporte e destinação. 
Gráfico 1: Classificação dos tipos de resíduos gerados e doados ao COOMVIDA.

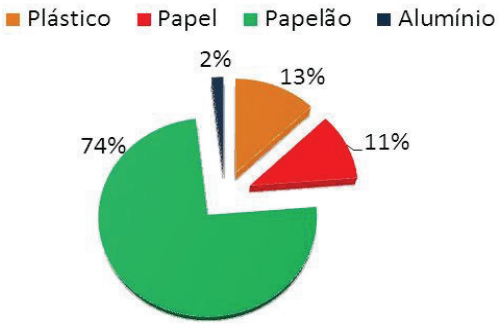

Fonte: COOMVIDA, 2013.
Tabela 4: Preço do Kg de cada resíduo.

\begin{tabular}{ccc}
\hline Material & \multicolumn{2}{c}{ Preço por $\mathrm{Kg}$} \\
\hline Papel & $\mathrm{R} \$$ & 0,30 \\
Plástico & $\mathrm{R} \$$ & 2,60 \\
Papeläo & $\mathrm{R} \$$ & 0,20 \\
Alumínio & $\mathrm{R} \$$ & 1,80 \\
\hline
\end{tabular}

Fonte: COOMVIDA, 2013.

O Gráfico 2 demonstra o incremento da geração dos processos das duas unidades da empresa, é possível verificar um aumento em torno de $55 \%$ na geração, o que tornaria as despesas ainda maiores, caso o projeto não tivesse sido implantado.

Podem ser citados vários benefícios causados pela mudança na logística de destinação dos resíduos recicláveis, na empresa do ramo de energia eólica. O maior impacto foi na redução dos custos que a empresa tinha com a prestadora de serviço de coleta, transporte e destinação dos resíduos. Nesse mesmo período de 2012 (fevereiro a outubro), foram gastos mais de R\$19.000,00 com coleta, transporte e destinação dos resíduos, como pode ser observado no Gráfico 3.

Gráfico 2: Demonstrativo do aumento da geração de resíduos sólidos gerados pelas unidades fabris.

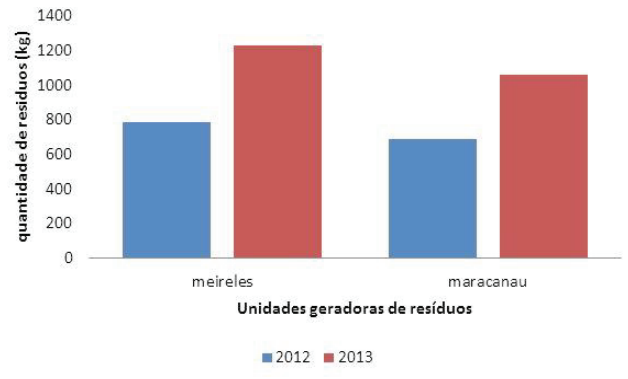

Fonte: COOMVIDA, 2013.
Gráfico 3 - Comparativo da quantidade de resíduos gerados em 2013 e 2012 versus o custo de descarte.

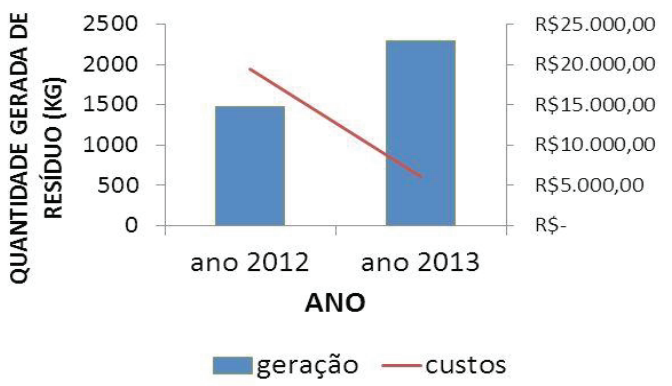

Fonte: COOMVIDA, 2013.

A operacionalização do projeto levou os custos com o processo de destinação a uma redução de até $70 \%$, quando comparado com o ano vigente. Outro fator considerável foi que, para a realização do referido projeto, não houve nenhum custo adicional para a empresa geradora de resíduos.

Diante da realidade do COOMVIDA, confirma-se que o cooperativismo, no segmento de trabalho e serviços, é uma das oportunidades administrativas que deveria ser analisada e avaliada com maior seriedade, pois representa uma nova relação de trabalho, com vantagens muito importantes e relevantes para todos os envolvidos no sistema. Para a cooperativa os três aspectos, foram considerados: infraestrutura, mão de obra e documentação legal eram fatores imprescindíveis para o atendimento às necessidades da empresa solicitante geradora de resíduos, e assim foi possível elevar o nível de arrecadação de cada cooperado, fatos como esse relatado são evidenciados sempre que analisamos a parceira empresacooperativa (HEIDEN, 2007).

\section{Conclusão}

A implantação da nova operacionalização na logística de destinação de resíduos sólidos da empresa do ramo de energia eólica foi importantíssima para alavancar o negócio da cooperativa COOMVIDA, uma vez que foi obtido aumento de faturamento no ano da realização do projeto, ou seja, 2013, quando comparado a 2012.

Ganhos intangíveis foram visualizados na realização deste projeto, dentre eles é possível citar que: os catadores possuem bastantes benefícios quando associados às cooperativas, melhoria da condição de trabalho, oportunidade de 
participação de programa de capacitação, aperfeiçoamento profissional e o desenvolvimento de atividades econômicas e sociais, proporcionadas pela cooperativa COOMVIDA, em parceria com a Prefeitura de Maracanaú.

A comunicação foi uma ferramenta propulsionadora ao estímulo da prática da coleta seletiva, acarretando melhor aproveitamento dos resíduos recicláveis dentro da empresa. Tal mecanismo elevou a geração e destinação correta dos resíduos, através da reciclagem e doação à cooperativa.

A operacionalização e a sistemática da gestão dos resíduos recicláveis pela cooperativa, doados pela empresa de energia eólica, foram satisfatórias.

Pode-se concluir que as doações ajudam muito no desenvolvimento e crescimento da cooperativa. Foi observado que o incremento financeiro da cooperativa foi de, aproximadamente, $\mathrm{R} \$ 600,00$ no total das doações.

Muitas famílias que antes tinham pouca ou nenhuma expectativa de vida, agora, quando mobilizadas e organizadas em cooperativas, podem planejar, discutir, construir e sonhar com melhores dias. Com o apoio da iniciativa privada e em parceria com órgãos públicos, projetos estão sendo desenvolvidos, construídos e executados de forma a criar mudanças nas organizações das comunidades de catadores, permitindo sua inclusão na sociedade.

\section{Referências}

ABEEÓLICA. Associação Brasileira de Energia Eólica. Disponível em: <http://www.portalabeeolica.org.br/index. php/nosso-setor.html>. Acesso em: 15 out. 2013.

ARAÚJO, D. O; SAMPAIO, G.M. M. S. Atuação do catador de material reciclável frente ao processo da reciclagem: uma revisão. Conexões Ciência e Tecnologia, Fortaleza, v. 7, n. 2, p. 9-26, jun. 2013.

ASSOCIAÇÃO BRASILEIRA DE NORMAS TÉCNICAS. NBR 10.004: classificação dos resíduos sólidos, Rio de Janeiro, 2004.

BENVINDO, A. Z. A nomeação no processo de construção do catador como ator econômico e social. $2010.95 \mathrm{f}$. Dissertação (Mestrado em Ciências Sociais) - Universidade de Brasília, Brasília, DF., 2010.

BONIN, L. E. Se os catadores de materiais recicláveis desaparecessem? Folha de São Paulo, 14 mar. 2012.

Disponível em: <http://empreendedorsocial.blogfolha.uol.com.br/2012/03/14/e-se-os-catadores-demateriais-reciclaveisdesaparecessem/>. Acesso em: 15 out. 2013

BRASIL. Lei ${ }^{\circ}$ 12.305, de 2 de agosto de 2010. Institui a Política Nacional de Resíduos Sólidos; altera a Lei no 9.605, de 12 de fevereiro de 1998; e dá outras providências. Diário Oficial da União. Brasília, DF, 3 ago. 2010. Disponível em: <http://www.planalto. gov.br/ccivil_03/_ato2007-2010/2010/lei/112305.htm>. Acesso em: 15 out. 2013.

Lei ${ }^{\circ}$ 5.764, de 16 de dezembro de 1971. Define a Política Nacional de Cooperativismo, institui o regime jurídico das sociedades cooperativas, e dá outras providências. Diário Oficial da União, Brasília, DF, 16 dez. 1971. Disponível em: <http://www. planalto.gov.br/ccivil_03/leis/15764.htm>. Acesso em: 13 set. 2013.

CONAMA. Resolução n 275/2001. Define o código de cores para os diferentes tipos de resíduos, a ser adotado na identificação de coletores e transportadores, bem como nas campanhas informativas para a coleta seletiva. Diário Oficial da União, Brasília, DF, 25 abr. 2001. Seção 1, p. 80. Disponível em: <http://www.mma.gov.br/port/ conama/legiabre.cfm?codlegi=273> . Acesso em: 23 out. 2013.

COOMVIDA. Cooperativa de Produção dos Catadores do Conjunto Vida Nova de Maracanaú. Fortaleza: [s.n], 2013.

GARCIA, E. E. C. Resíduos sólidos urbanos e a economia verde. Disponível em: <http://fbds.org.br/fbds/IMG/pdf/ doc-667.pdf>. Acesso em: 3 fev. 2014.

HEIDEN, A. I. Von Der. Cooperativas de reciclagem de lixo e inclusão social: o caso do município de Itaúna, Minas Gerais. 2007. 93f. Dissertação (Mestrado) - Universidade do Estado de Minas Gerais, Belo Horizonte, 2007.

JACOBI, P. R.; VIVEIROS, M. Da vanguarda à apatia, com muitas suspeitas no meio do caminho - gestão de resíduos sólidos domiciliares em São Paulo entre 1989 e 2004. In: JACOBI, P. (Org.). Gestão compartilhada de resíduos sólidos no Brasil: inovação com inclusão social. São Paulo: Annablume, 2006. v. 1, p. 17-64.

MARTINS, C. H. B. Trabalhadores na reciclagem do lixo: dinâmicas econômicas, socioambientais e políticas na perspectiva de empoderamento.2003.210f. Tese (Doutorado) - Universidade Federal do Rio Grande do Sul, Porto Alegre, 2003. 
MILLER JR, G. T. Ciência ambiental. São Paulo: CENGAGE Learning, 2008.

PAIVA, F. V. Resíduos sólidos: potencial ambiental e comercial. Fortaleza: Demócrito Rocha, 2011.

PEREIRA, M. C. G; TEIXEIRA, M. A. C. A inclusão de catadores em programas de coleta seletiva: da agenda local à nacional. Cadernos EBAPE.BR, v. 9, n. 3, Rio de Janeiro, p. 895-913, set. 2011.

PEREIRA NETO, T. J. A política nacional de resíduos sólidos: os reflexos nas cooperativas de catadores e a logística reversa. Diálogo, n. 18, p. 77-96, 2011.

SANTOS, J. G. A logística reversa como ferramenta para a sustentabilidade: um estudo sobre a importância das cooperativas de reciclagem na gestão dos resíduos sólidos urbanos. REUNA, Belo Horizonte, v. 17, n. 2, p. 81-96, abr./ jun. 2012.

SILVA, J. R.; PENNA, L. F. da R. Coleta seletiva de resíduos sólidos urbanos: estudo de caso em Governador Valadares-MG. 2013. 16f. Trabalho de Conclusão de Curso. (Graduação) - Universidade Federal de Minas Gerais, 2013.

SIMAN, L. M. A importância das associações de catadores de materiais recicláveis na gestão de resíduos sólidos urbanos: o caso da Associação dos Catadores de Materiais Recicláveis Natureza Viva (ASCANAVI) Governador Valadares-MG. 2013. 21f. Trabalho de Conclusão de Curso (Graduação) - Universidade Federal de Minas Gerais, 2013.

RICHIERI, S. M. M. Estudo do impacto das mudanças climáticas globais nos mangues tropicais. 2006. 117f.

Dissertação (Mestrado em Engenharia de Processos Químicos e Bioquímicos) - Escola de Engenharia Mauá, Rio de Janeiro, 2006.

\section{Sobre os autores}

\section{Nicole Rios Tavares}

Engenharia Ambiental e Sanitária pela UNIFOR em 2013. Atualmente, trabalha em ZIATECH Construções LTDA. Trabalhou na Suzlon Group como analista de meio ambiente e engenheira ambiental trainee, de outubro 2012 a maio de 2014.

\section{Adriana de Oliveira Sousa Leite}

Graduada em Química Industrial pela Universidade Federal do Ceará (1994), mestrado (1999) e doutorado (2004) em Química Inorgânica pela UFC. Profissional Green Belt pela Fa7 em 2014. Especialista em processos químicos (tratamento de superfície, pintura, esmaltação). Experiência em sistema de gerenciamento da qualidade e de produção, coordenação de produção em setores como fundição de não metais, pintura industrial, esmaltação e moinhos. Coordenação de laboratórios de controle de produção e desenvolvimento. 